\title{
Correction to: Recombination between homoeologous chromosomes induced in durum wheat by the Aegilops speltoides Su1-Ph1 suppressor
}

\author{
$\mathrm{Hao} \mathrm{Li}^{1,2} \cdot$ Le Wang $^{2} \cdot$ Ming-Cheng Luo $^{2} \cdot$ Fang Nie $^{1} \cdot$ Yun Zhou $^{1} \cdot$ Patrick E. McGuire ${ }^{2} \cdot$ Assaf Distelfeld $^{3}$. \\ Xiongtao Dai ${ }^{4}$. Chun-Peng Song ${ }^{1}$. Jan Dvorak ${ }^{2}$
}

Published online: 1 October 2019

๑) Springer-Verlag GmbH Germany, part of Springer Nature 2019

Correction to: Theoretical and Applied Genetics https://doi.org/10.1007/s00122-019-03423-z

Unfortunately, the 9th author name was incorrectly published in the original publication. The complete correct name is given below.

Chun-Peng Song

The original article has been corrected.

Publisher's Note Springer Nature remains neutral with regard to jurisdictional claims in published maps and institutional affiliations.

The original article can be found online at https://doi.org/10.1007/ s00122-019-03423-z.

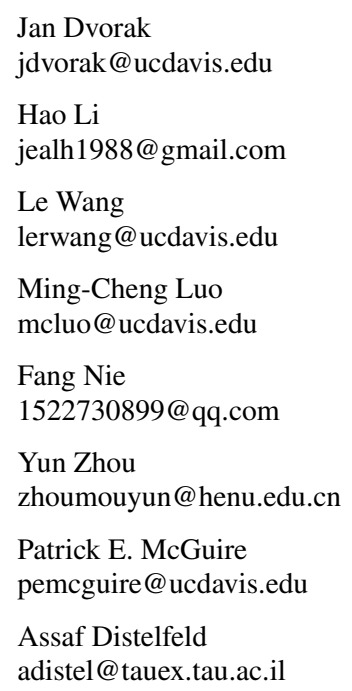

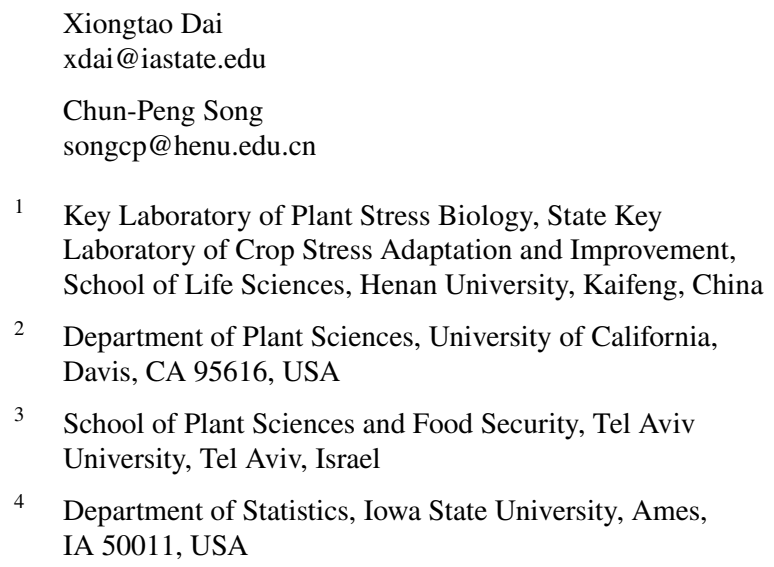

